\title{
The fundamental violence of physiotherapy: Emmanuel Levinas's critique of ontology and its implications for physiotherapy theory and practice
}

\author{
Filip Maric ${ }^{1}$, David Nicholls ${ }^{2}$
}

1. Environmental Physiotherapy Association (EPA), Oslo, Norway.

2. School of Clinical Sciences, Auckland University of Technology, New Zealand.

Submitted: 14 May 2019 | Accepted: 12 May 2020

\begin{abstract}
The fundamental role of ontology, epistemology, and ethics is widely recognised across the healthcare professions. Yet what is less known in physiotherapy is how ontology and epistemology potentially undermine the ethical intentions of our theories and practices. In this article, we draw on the work of 2oth-century philosopher Emmanuel Levinas to highlight this problem. Particularly Levinas's ethical critique of ontology and the associated notion of thematisation enable us to highlight a violence that takes place in the philosophical foundations of physiotherapy. Using the overarching aims of physiotherapy, the theory and practice of diagnosis, and the notion and enforcing of professional identities as examples, we additionally show how this violence consequently pervades physiotherapy theory and practice. By exploring a range of critical and practical implications, we finally show how an application of Levinas's critique of ontology additionally opens toward an otherwise physiotherapy grounded in a renewed understanding of self, other, and their relation. With this, we hope to highlight the core value and critical need for a deeper engagement with the work of Levinas in relation to all aspects of physiotherapy, and particularly its understanding and implementation of ethics that is so fundamental to its practice and a cornerstone of physiotherapy education.
\end{abstract}

Keywords: ethics, self, other, ontology, epistemology, positivism

\section{Background}

Emmanuel Levinas's critique of ontology and his radical renewal of ethics has had a lasting influence well beyond the confines of philosophy. It has greatly inspired research in areas as diverse as social and political theory, theology, arts and design, legal theory, international relations, and pedagogy (Critchley, 2002). Increasing interest in Levinas's ethics in healthcare theory and practice has also seen his writings explored in psychotherapy, medicine and nursing (Burcher, 2011; Clifton-Soderstrom, 2003; Naef, 2006; Nortvedt, 2003; Surbone, 2005). Beyond a few very brief forays, however, Levinas's work remains underexplored in physiotherapy (Dufour, Brown, \& Lucy, 2014; Lund Kordahl \& Fougner, 2017). This is unfortunate given the radical and fundamentally transformative potential that his critique of ontology and his otherwise ethics would have for physiotherapy theory and practice. This paper, therefore, sets out to introduce the reader to Levinas's critique of ontology and the associated concept of thematisation, and open a conversation about their critical and practical implications for physiotherapy.
The central importance of ethics and ethical relations in healthcare is widely recognised across the healthcare professions. A growing body of research has sought to refine our understanding and responses to increasingly complex ethical challenges in clinical practice, research, and education (Dahl-Michelsen \& Groven, 2017; Kulju, Suhonen, \& Leino-Kilpi, 2013; Lillemoen \& Pedersen, 2012; Murray \& Holmes, 2009; Swisher, 2002). Consequently, professional guidelines are identifying ethics as 'fundamental to the practice of physiotherapy', and professional bodies around the world are looking to provide professionals with the knowledge and tools necessary to meet the ethical challenges they might face now and into the future (PBNZ, 2011, p. 4).

Similarly, ontology (the study of existence and being, asking, e.g. how things are and come to be), and epistemology (the study of knowledge and its acquisition, asking, e.g. how we come to know about things), are generally considered the foundations of all thought and scientific endeavour. The ontological and epistemological foundations of positivism and biomedicine stand out in the world of healthcare, having dominated research and practice for the past centuries (Nicholls, 2018; Gibson \& Martin, 2003; Grant \& Giddings, 2002). As such, they have provided the philosophical foundations for modern-day evidence-based physiotherapy, 
though recent years have seen a steady rise in the exploration of other philosophical paradigms and the divergent practices they can provide a foundation for (Gibson, Nicholls, Setchell, \& Groven, 2018). What is less known in physiotherapy, however, is how ontology, epistemology and ethics relate to each other, and how fundamental this relationship is to physiotherapy. Levinas's work provides invaluable insights here. It allows us to understand the relationship and application of ontology, epistemology and ethics better and apply this to the further development of physiotherapy theory and practice.

We begin this article with a brief overview of Levinas's personal life and philosophical trajectory, and an exposition of his understanding and ethical critique of ontology and the violence of thematisation. We review how this critique applies to physiotherapy by reviewing (1) the philosophical foundations of physiotherapy; (2) the overarching aim of physiotherapy; (3) the theory and practice of diagnosis; and (4) the notion and enforcing of professional identities. We conclude the article with a range of implications for physiotherapists looking to apply Levinas's critique of ontology to theory, research, and practice.

In line with the implications of Levinas's critique of ontology, this paper calls on physiotherapists to carefully consider the unintended, yet inherent violence in relating to others from a position of knowledge. The paper also calls on physiotherapy educators in two distinct, though philosophically overlapping ways: firstly, by urging them to consider the philosophical foundations they are passing on to future physiotherapists, and via these, also future healthcare beneficiaries; and secondly, to reconsider their education theories and practices from this perspective with their student's as their primary 'others' in mind.

Our theses are: (a) that there is a significant violence inherent in the philosophical foundations of contemporary physiotherapy that is easily overlooked yet continuously enacted in its day-to-day theories and clinical practices; and (b) that the exposure of this violence calls for an otherwise physiotherapy that more accurately 'captures the ethical core and central values of healthcare' (Nortvedt, 2003, p. 25).

The implications of this exposure are positively radical, questioning the very roots of our professional understanding and practices, and so everything built upon them. To the extent that they call for the development and implementation of radically otherwise theories and practices, there is no questions that sizeable constraints and limitations posed by existing social, professional, institutional, and legal boundaries surrounding physiotherapy

would have to be dealt with in their wake. Rather than engaging with these here, however, in this article, we choose to think with Levinas in the extreme. That is to say, we choose to think about physiotherapy through and with one aspect of his work - the critique of ontology - without constraining this by either pragmatic concerns, or even other aspects of his work that qualify it.

This is not to say that we should not consider such concerns and qualifications, but rather that we relay them to future research and publications. In light of the relative novelty of Levinas's work in physiotherapy, our hope here is that this article will highlight the critical need for a deeper engagement with his work and its various benefits and limitations. We believe this to be necessary because ethics is critical to physiotherapy, and because Levinas's work provides an underexplored perspective on ethics with radically transformative implications for our professional theories and practices.

\section{Emmanuel Levinas - a brief introduction}

Born in 1906 in the Jewish community of Russian-occupied Kovno (now Kaunas, Lithuania), Levinas's upbringing was steeped in both Jewish thought and the classical Russian literature. Reflecting on this time in several interviews, Levinas speaks of Judaism as that which 'one breathed ... in with the air' on the one hand (Levinas \& Anissimov, 2001, p. 84), and with reference to Russian literature, as that which led him to the philosophy of the other, 'specifically Pushkin, Lermontov, and ... above all Dostoyevsky' (Levinas \& Poirié, 2001, p. 28). Levinas found the novels of Dostoyevsky and Tolstoy 'preoccupied with fundamental things ... readable as a search for the meaning of life' (Levinas \& Poirié, 2001, p. 28).

Choosing 'France on account of the prestige of the French' and in France, 'the city closest to Lithuania' Levinas went on to study philosophy in Strasbourg in 1923 (Levinas \& Poirié, 2001, p. 28). There, he read classical philosophical works from Plato and other Greek philosophers through to Descartes, but also famous contemporary philosophers of the time like Henri Bergson. An academic year spent in Freiburg, Germany, during which he met and studied under the famous phenomenologists Edmund Husserl and Martin Heidegger, was, however, particularly significant to the development of his future method and thought.

Highly impressed by both of these thinkers, Levinas engaged deeply with both of their works, as is evident very early on in the publication of his doctorate thesis on The Theory of Intuition in Husserl's Phenomenology in 1930 (Levinas, 1995). Though he played a major role in introducing Husserlian phenomenology to French philosophers like Sartre and others as a result of this publication, Levinas would later recount that the main import of Husserl to his own work was in providing 'a method for philosophy' that enabled one to 
'listen acutely for what is implicit', to pay 'special attention to what is allusive in thinking' (Levinas \& Malka, 2001, p. 94-95). Levinas argued that building on Husserl's method of phenomenological reduction, and the general sentiment that phenomenology enabled one to get behind the appearance and to the very essence of phenomena, eventually enabled him to explore the limits of being and knowledge, and in this limit, 'a forgotten experience from which it lives' (Levinas, 1969, p. 28).

The relation to Heidegger would prove more difficult, though even more influential, as it was Heidegger that became Levinas's 'most important philosophical rival, providing the philosophical resources, constraints, and pressure' against which Levinas would eventually develop his argument for 'ethics as first philosophy' (Fagenblat, 2018, p.3). To fully appreciate how Heidegger's work became so crucial to the shaping of Levinas's philosophy, it is necessary to consider Levinas's experience of the Second World War. Levinas was profoundly shaken by Heidegger's affiliation to National Socialism, his membership of the Nazi Party, and Heidegger's public political commitment to its project. Levinas simply could not understand, as Critchley explains, 'how a philosopher as undeniably brilliant as Heidegger could have become a Nazi, for however short a time' (Critchley, 2002, p.8).

Notwithstanding his antipathy towards Heidegger's position, the rise of Nazism during WWII was the more profoundly affecting experience. As Levinas himself would repeatedly state, his life and work were 'dominated by the presentiment and the memory of the Nazi horror' (Levinas, 1990, p. 291). Being incarcerated as a prisoner of war very early on, he found himself in a peculiar and somewhat paradoxical situation during this time. Recognised and segregated as a Jew, yet spared by his French uniform and the immunity it provided as a result of the Geneva convention, Levinas spent the war working, and even reading and writing philosophy in a prison camp virtually cut off from the outside world. It was only after being freed that Levinas learned of the full extent of the Nazi atrocities: 'the horrors of the camps'; the killing of his entire family; and the murder of 6,000,000 fellow Jews and countless others (Levinas \& Poirié, 2001, p. 42).

Much like for so many other philosophers and non-philosophers alike, the bigger question that posed itself after WWII then was ultimately how Nazism, and all of the atrocities that were enacted in its wake, were even ever possible. Levinas wrote in Totality and Infinity - his first major work, that, 'Everyone will readily agree that it is of the highest importance to know whether we are not duped by morality' (Levinas, 1969, p. 21). In other words, Levinas's broader, central question became whether it was still possible and sensible to speak of ethics after its failure in WWII, 'whether we can still believe in morality after Auschwitz', and if so, how might this be possible (Bernstein, 2002, p. 254)?

It is in relation to this question that the full significance of Heidegger's thought on Levinas's work became clear, as it was Heidegger's thought that 'provided a way of understanding the deep philosophical roots of the weed that was Hitlerism' (Fagenblat, 2018, p. 12). And although Levinas never entirely conflated Heideggerian philosophy with Hitlerism (Fagenblat, 2018), he still found in it philosophical access to 'a crisis that is much more profound, and older' (Levinas, 1989, p. 207). It is this crisis that Levinas ultimately turned his attention to in his 'critical questioning of Heidegger's project of fundamental ontology' and his search for an otherwise fundamental philosophy that could provide the grounds for a different, ethical way of being (Critchley, 2002, p. 9). Due to the breadth of Levinas's philosophical work and the diverse implications that can be drawn from his works we have restricted this article to Levinas's critique of the philosophical foundations of a vast majority of Western philosophy which, in primary reference to Heidegger, he referred to as ontology. Further overviews of Levinas's philosophical oeuvre can be found his own writings, as well as many other publications covering various aspects of his life (Bergo, 2007; Critchley \& Bernasconi, 2002; Levinas, 1990; Levinas \& Nemo, 1985; Malka, 2006; von Wolzogen, 2005). Of particular relevance here, however, is the development of Levinas's critique of the violence of ontology.

\section{Thematisation - the violence of ontology}

Heidegger's work continues to exert wide influence in and outside of philosophy despite his affiliation with National Socialism, with his magnum opus - Being and Time remaining his most influential study (Heidegger, 2008). Heidegger wrote Being and Time as an attempt to uncover the fundamental nature of existence or being (Sein) through a phenomenological analysis of human existence (Dasein) (Korab-Karpowicz, 2019). According to Levinas, Heidegger's analysis led him to argue that 'being' itself is the fundamental ground of existence, because its main characteristics are its 'being there' (Dasein) and 'being conscious' of itself.

Though Levinas held Being and Time in the highest regard, he ultimately used it as the backdrop for the development of his critique of ontology, beginning with a concern about the self-referential idea of existence proposed by Heidegger. Levinas argues that Heidegger's ontology is essentially epistemological because it essentially advances the idea that existence comes into being with and through knowledge of itself. Thus understood, epistemology (knowledge and knowing) is the fundamental mode of being (ontology) (Levinas, 1987). In arguing for this conflation of ontology and epistemology, Heidegger's work merely perpetuates what 
Levinas perceives to be the central problem of the entire Western philosophical tradition since Plato (Critchley, 2002).

The consequences of this conflation then form the central motivation for Levinas's critique of Western philosophy, all the way through to Heidegger's fundamental ontology. To Levinas, Heidegger's ontology describes a situation where knowledge, or knowing is the first and foremost way that humans exist in and interact with the world (Levinas, 1969). This has two implications for everyone or everything different from being, or other than the self. First, it implies that the other, as much as the relationship to the other, is secondary to the self. Already in itself, to consider human existence as always concerned with self before being concerned with others will rightly seem problematic ethically speaking.

The problem is exacerbated by the second implication, which is that knowledge becomes the first and fundamental way in which one can relate to anything, or anyone else. Everything and everyone other than self is only ever approached and engaged with from a perspective of knowledge (Critchley, 2002). From this perspective, the other is already defined and identified as a knowable entity, something that can be known and that cannot and will not exceed the limits of knowledge.

Moreover, because knowledge is but a version of or expression for the self, the other is never allowed to be genuinely and distinctly other. Worse still, because there can be nothing outside of the self and its knowledge, the other is never allowed to exist in the first place. In a world based on being and knowledge and, therefore, without others, however, there are no relationships and, ultimately, no ethics.

Levinas used a variety of terms to describe this dramatic effect of knowledge and understanding it as fundamental, from reducing and limiting the other, through suppression, assimilation and, finally, undoing and annihilation of the other and all otherness. In his own words, 'the known is understood and so appropriated by knowledge, and as it were, freed of its otherness' (Levinas, 1989, p. 76). Entering into a relationship to come to know the other is violent because it implies this limitation of the other. By reducing the other to the epistemological capacities of the self and the categories of its knowledge, knowing, effectively, denies and ends the existence of the other, the ultimate violent act.

The following quote by Simon Critchley provides a particularly lucid and visual reiteration of Levinas's argument. Because it matches the critique of knowledge with terminology related to movement and the use of hands, it should be additionally familiar to physiotherapists:

'In ontology, the other is assimilated... like so much food and drink... ontology is the movement of comprehension, which takes possession of things through the activity of labor, where conceptual labor resembles manual labor. Ontology is like the movement of the hand, the organ for grasping and seizing, which takes hold of (prend) and comprehends (comprend) things in a manipulation of otherness' (Critchley, 2002, p. 16).

Levinas eventually refers to violence exerted by knowledge as thematisation or totalisation. This is, firstly, in reference to the way the other is approached and objectified as something knowable, a 'theme'. And, secondly, in reference to the way the other is assimilated into the encompassing totality of the self via the movement of comprehension (Levinas, 1969). Whichever terms we use though, the full strength of Levinas's critique of theoretical frameworks based on ontology and epistemology or, knowledge, lies in their exposure as philosophies of power (Levinas, 1969, p. 46).

It might be tempting to argue that the scathing language Levinas uses to express the violence of thematisation is hardly appropriate, given its seemingly abstract, conceptual nature. To better understand this then, we should remember that Levinas was primarily concerned with the underlying conceptual, or philosophical foundations that enable violence against others in the first place and irrespective of scale. At this fundamental level, there is no difference between the conceptual and the physical annihilation of the other. Furthermore, if we understand that this conceptual foundation is necessary for more noticeable, physical violence against others to take place, then it should be evident how important it is to address the problem at its root rather than its branches. We keep our focus aligned with this in the present article, rather than engage in an attempt to qualify what kind of violence might be more or less bad.

With this in mind, the case Levinas makes is of grave importance to those who think and practice in the health arena. His critique strikes at the heart of what it means to be a healthcare professional, where being a professional is first and foremost defined by what we know about health, illness and those in our care and how we act on the basis of this knowledge. Radically speaking, Levinas's critique of ontology and the exposure of its violence of thematisation challenges the entire philosophical basis of Western healthcare, arguing that it is fundamentally violent and, ultimately, unethical.

\section{The fundamental violence of physiotherapy}

Mainstream contemporary physiotherapy builds on Western science and medicine, both of which are firmly grounded in ontology and epistemology as outlined here. As a result, the violence of thematisation inevitably pervades the profession's most fundamental theoretical concepts, as well as the clinical and professional practices built on these. In this section, we first turn our attention to the philosophical foundations of 
physiotherapy to extrapolate how this is the case there, before looking at how this fundamental violence plays out in three different areas of clinical and professional theory and practice: the overarching aims of physiotherapy, the theory and practice of diagnosis; and the notion and enforcing of professional identities.

\section{The philosophical foundations of physiotherapy}

Levinas's critique of ontology and its inherent violence are particularly relevant to the philosophical foundations of physiotherapy, because they lay the groundwork for its application to other professional theories and practices. As with nursing, midwifery, occupational therapy, and other orthodox health professions, the philosophical foundations of physiotherapy have had a longstanding affinity with biomedicine. This is, in part, because the medical profession established itself as the pre-eminent healthcare profession in the developed world after the middle of the nineteenth century. Biomedicine brought forward significant advances in the scientific method, and aggressively promoted positivism and Enlightenment principles of the primacy of the autonomous, self-determining and sovereign human (Nicholls, 2018).

Physiotherapy followed biomedicine in adopting the idea of a single objective reality (Nicholls, 2009). This belief upheld a number of critical assumptions underpinning the scientific basis of physiotherapy theory and practice, including the belief that reality, phenomena, or objects exist separate and independent of subjective experience, or subjectivity. This view held that every object has a distinct nature, or essence of its own; which, thanks to its separate nature and existence, can be distinguished, observed, and identified through the rigorous application of scientific methods. Critically, other entities - including people, bodies, actions, intentions, values and beliefs - can be known by a knowledge-gaining and knowledge-bearing subject (Crotty, 1998; Grant \& Giddings, 2002).

The belief in a single objective reality and the related fundamental assumptions of positivism have been extensively critiqued elsewhere (Giddings \& Grant, 2007; Proietti et al., 2019). Although never before applied directly to physiotherapy, our contention is that Levinas challenges the positivistic basis of physiotherapy and both its ontological relation to reality in which the object-other is identified and approached as a knowable, or thematisable entity; and its belief that the practitioner is the knowing, doing ego; the expert that identifies, gains and defines knowledge about the other (Grant \& Giddings, 2002, p. 14-15).
In recent years, other critiques of the positivism inherent in evidence-based biomedicine (and, by extension, physiotherapy) have emerged, not least from those advocating for person-centred care, holistic medicine, qualitative research, narrative-based medicine and the humanities (Clifton- Soderstrom, 2003; Gibson \& Martin, 2003; Greenhalgh, Howick, \& Maskrey, 2014; Holmes et al., 2006; Miles, Loughlin, \& Polychronis, 2008; Shaw, 2012). Levinas's work, however, enables us to go much further than these and argue that positivism, upon which biomedicine is based, leaves no room for difference. Biomedicine, then, limits the otherness of the other through an 'imposition of scientific language on illness experiences which universalises persons into general categories' without fully acknowledging their particular and unknowable otherness (Clifton-Soderstrom, 2003, p. 459).

As explained in the preceding section, Levinas developed his critique of thematisation in response to Heidegger's fundamental ontology, which in turn is tied to the latter's understanding of application of phenomenology.

Phenomenology, in turn, developed at least partly as a response to positivist sciences and represents an early acknowledgement of the limitations of objectivity (Grant \& Giddings, 2002). Insofar as phenomenology is utilised as a means to accumulate knowledge however, there is no substantial difference between phenomenology and positivism from a Levinassian perspective.

Levinas's critique directly targets positivism's desire to manipulate reality and 'explain, predict or control events' (Critchley, 2002, p. 16). As argued elsewhere, the desire to know and control phenomena lies at the 'philosophical heart of all clinical trials, experimental and quasi-experimental designs, epidemiological surveys, single-incidence studies, tests of validity and reliability, and a plethora of other quantitative designs' (Nicholls, 2009, p. 528). The epistemological tools employed by positivism, phenomenology and other methodologies aimed at accumulating knowledge adhere to the same ontological and epistemological foundations (Grant \& Giddings, 2002, p. 13-14). They build on the assumption that reality can (and must) be known and that knowledge is the primary mode through which reality should be encountered.

Modern physiotherapy builds on and promotes knowledge as the basis for ethical and clinical decision making and the prediction of rehabilitation trajectories. Levinas's critique, therefore, directly relates to the philosophical foundations of physiotherapy and everything that builds on them. This is especially important if we realise that engaging these philosophical foundations in the search for knowledge constitutes an action or practice in itself. It is limiting and reducing the phenomena we encounter to that which our knowledge can encompass and taking away their possibility to 
be otherwise or different, thus reiterating the fundamental violence of thematisation.

Highlighting this practical side is crucial insofar as it shows that the violence of thematisation is immediately and inherently far from merely conceptual. This violence is enacted as soon as we approach the other as a knowable entity, suffering from an entirely knowable phenomenon. Because this is quintessentially what evidence-based practice implies we can begin to recognise how professional theories and practices that build on these foundations inevitably perpetuate the problem.

\section{The aim of physiotherapy}

The overarching aim of physiotherapy provides a pertinent example of how thematisation plays out in other areas of the profession because they more overtly guide what we do in everyday clinical practice. A growing number of researchers are showing that the philosophical foundations of physiotherapy have shaped some of its central concepts and professional practices, often in a manner that is reductive and restrictive to diversity or otherness. This has been argued with regard to physiotherapy's notions of the body, movement, function, normality, and therapeutic touch (Allen, 2007; Bähr, Nicholls \& Holmes, 2012; Cott, Finch, \& Gasner, 1995; Gibson, 2014; Gibson \& Teachman, 2012; Jorgensen, 2000; Rosberg, 2000; Wikström- Grotell \& Eriksson, 2012). Considering the Levinassian critique of ontology allows us to interrogate how the profession's aim exerts a, paradoxically, similarly delimiting or disabling violence on those it seeks to aid.

According to the World Confederation for Physical Therapy (WCPT), one of the foremost aims of physiotherapy is 'to provide services that develop, maintain and restore people's maximum movement and functional ability' (WCPT, 2016). Taken by itself, this aim resonates closely with Levinassian sentiments against limiting others to one or another knowledge-based category. Especially in the aspiration to 'develop, maintain and restore people's maximum movement', it sets up physiotherapy as a profession primarily focussed on taking down barriers to maximum mobility and further supporting it.

If we now consider Levinas's notion of 'otherness' from an etymological perspective, we will soon find its resonance to the aim to maximise movement. Levinas often uses alterity as an alternative term for otherness, with both terms essentially meaning the same. To reduce otherness, then, means to reduce the other's ability to be alter, or other than knowledge, to exceed the limits imposed by knowledge. Etymologically, this ability to (be) alter or change precisely implies the ability to be mobile, that is, able to move (Harper, 2019). Thus understood, Levinassian ethics could be said to aim at maximum (epistemological) movement wherever this is limited and not only condemns any such limitation as disabling, violent and even unethical.

A problem arises, however, where what counts as movement is further defined in terms of knowledge gained through the application of epistemological tools. Given its broader context as a healthcare profession, the aim of physiotherapy is, for example, heavily influenced by the World Health Organisation (WHO) definition of health as 'a state of complete physical, mental and social well being and not merely the absence of disease or infirmity' (WHO, 1948). Translated in terms of physiotherapy's overarching aim, this state of wellbeing must be associated with maximum movement and functional ability. The issue here, however, is that to equate maximum movement with a state is a contradiction in terms because a 'state' quintessentially implies a lack of movement, a standing still.

That determining the state of health is indeed what the WHO invests in is also visible in the WHO's International Classification of Functioning, Disability \& Health (ICF). The ICF provides a tool for the comparison and measurement of 'levels of health', using 'optimal health' as its benchmark, a 'common metric ... applicable to all people irrespective of health condition' (WHO, 2002, p. 3). The use of epistemological tools and practices like measurement, calculation, quantification and scaling clearly shows the extent to which WHO's definitions of health and function are grounded in positivist ontological assumptions. As such, however, they also perpetuate the violence of thematisation, making movement and function 'themes' that can be defined and that further serve the ranking of people according to (thematic) levels of function.

Building on WHO's definitions of health and functioning, physiotherapy commonly considers movement in rather narrow terms as, for example, physical ranges of movement of specific joints, or time spent engaging in physical activity at particular heart rates. Keeping in mind how doing so effectively contradicts the aim of supporting maximum movement in a broader sense, thus affords a possibility to review what we do before a more rigorous, ethical understanding of our professional aim. If the aim of maximum movement were followed through more consistently, physiotherapy could effectively work in tandem with Levinassian ethics. That is, as practices aimed at supporting, maintaining, and restoring mobility at any level, physical, mental, epistemological, or else.

\section{The theory and practice of diagnosis}

The theory and practice of diagnosis provide another example of how thematisation is enacted in physiotherapy. As Beavers 
(1993) argued in his reading of Levinas and the notion of thematisation, the 'first act of violence occurs whenever I limit the other to a set of rational categories, be they racial, sexual, or otherwise' (Beavers, 1999, p. 3). Translated to the context of clinical practice, this means that the thematisation happens in the application of diagnostic procedures to a client presenting with health problems.

Standard approaches to practice mandate that patients are approached, observed, interviewed, and examined from the perspective of our professional knowledge, and diagnostic categories of mainstream healthcare are applied. Without a doubt, putatively individual factors, such as client goals, are also considered in this process. However, they mostly serve the process of establishing a diagnosis according to specialised, epistemological, diagnostic labels like 'lumbar sprain', 'subacromial pain syndrome', and 'plantar fasciitis'.

The issue with such diagnostic labels from a Levinassian perspective, however, is that they facilitate a reduction and limitation of a client to nothing but 'that hip I see on Tuesdays', 'the ACL in room 4', and so on. In doing so, the act of diagnosis incapacitates and immobilises the other by disabling the client to go or be anything beyond the epistemological and operational category it provides.

Existential philosopher Søren Kierkegaard purportedly expressed the sentiment that 'once you label me, you negate me', which strongly resonates here (McManus, 2019). The diagnostic label constrains the potential to be 'other' than the label. By additionally grouping the client in with similarly labelled other 'shoulders', 'knees', or else, it further reduces the particularity of each individual client. As a result, the act of diagnosis itself might, paradoxically, oppose 'the ethical foundation of medicine' (Clifton-Soderstrom, 2003). This foundation is precisely to support the other in their individual and irreducible otherness or, as expressed in the aim of physiotherapy, to maximise their mobility.

There are many nuances to the theory and practice of diagnosis that we cannot explore in the context of this article. Diagnostic labels have undoubtedly also played a significant role in advancing medical science and treatments, not least through the reductive focus they enable. In their day-to-day clinical application, they are certainly also not applied with ill-intention but, in fact, the precise contrary. Looking at diagnosis from a Levinassian perspective, however, enables us to see how a subtle, but significant violence nonetheless takes place and underlies one of our most basic professional practices. Because it is so contrary to our professional aspiration to maximise movement, we believe that to draw attention to it is of utmost importance. As such, it might need careful review to prevent it from incapacitating and immobilising those in our care, rather than developing, maintaining, and restoring mobility.

\section{Professional identity}

Thematisation is not only relevant to patients, but also affects physiotherapy professionals, particularly in the way we understand and construct professional identity. In itself, the notion of identity stands in contrast to Levinas's emphasis on (individual) difference as a fundamental ethical requirement. Levinas would often express these in his critique of terms like identity, sameness and identification, which effectively translates to 'making same'.

Professional identity then quintessentially implies a 'making same' of a group of professionals and already as such contrasts or delimits any more radical take on diversity. It enables only diversity within defined parameters. The WCPT, for example, promotes the notion that certain personal and professional behaviours, values, codes and practices are an integral part of a physiotherapists professional identity (WCPT, 2011a). The objective identification and normative codification of parameters like these further narrow the fundamental limitation already implied in the term 'professional identity'. This additional narrowing down, however, is what is necessary to homogenise a disparate group of individuals into 'physiotherapists'.

Not surprisingly, the development of professional sameness is also a critical element built into professional education. It first takes place in undergraduate education, as physiotherapy students 'attain the knowledge, skills, and attributes described in the guidelines for physical therapist professional entry-level education' (WCPT, 2011b). Continuing professional development then further promotes the idea that the knowledge, skills, and attributes acquired in undergraduate education need to be maintained, developed and enhanced on an ongoing basis to retain one's standing (i.e. identity) as a physiotherapist. In the same wake, regulatory authorities are deployed to ensure that a practitioner's personal values do not transgress their professional identities.

On the one hand, we could argue that undergraduate education represents a time of self-development insofar as one's self is changed throughout its course. On the other hand, however, this development is directed towards a pre-determined professional identity. Whether as a replacement or addition to self-development, the aim of this process is the development of a homogenous professional identity distinguishable from the heterogeneous personal selves of the thousands of people that become therapists. While the WCPT's definition of CPD implies that personal skills, knowledge, and behaviours are supplementary to professional ones, their distinction as such ultimately affirms 
their difference and the further exclusion of the personal from the professional (WCPT, 2011a).

The supplementary and subordinate relationship of personal to professional identity is also evident in the kinds of reflective practice and supervision advocated for by professional bodies internationally. Supervision, for example, is aimed at 'helping the development of a professional identity' (PNZ, 2012, p. 1), while professional self-reflection aims at 'improving or affirming... professional practice' (PBNZ, 2011, p. 22). Both practices then perpetuate the development and ongoing conformity of professional identity over the development of more personal modes of reflection. As practices of identification, they aid in aligning physiotherapists with their professional group-identity, and, so, subordinate, assimilate, exclude, reduce, and even undo the unique and idiosyncratic otherness of the practitioner.

Though there are undeniable variations amongst professionals, the ongoing definition and implementation of a broad professional identity that constrains personal diversity thus prevail throughout our professional practices. From a Levinassian perspective, this professional identity presents a restricted category that enacts that same violence of thematisation on its very own members. For a profession that aspires to 'develop, maintain and restore people's maximum movement' this seems an irreconcilable tension at its very heart (WCPT, 2016).

\section{Toward an otherwise physiotherapy}

This brief review of the aim of physiotherapy, the theory and practice of diagnosis, and the concept and development of professional identity highlights how firmly physiotherapy is grounded in (positivist) ontology and epistemology. Building on Levinas's critique of ontology this implies that physiotherapy perpetuates the fundamental violence of thematisation, that is, the reduction and limitation of all otherness to the categories and capacities of knowledge and the knowing (professional) self. This, however, also means that physiotherapy also enacts an inadvertent limitation, rather than the mobilisation of otherness. Applying Levinas's critique of ontology to physiotherapy, thus, implies a radical critique of the profession in the original sense of the term radical. It exposes the (epistemological) violence of thematisation at the 'roots' of physiotherapy.

A sizable issue that this radical critique raises is that it appears to leave the profession with little theories or practices to work with that are not fundamentally violent. If the knowledge with which we identify and the practices that we develop restrain the other, rather than enable movement, what justification is there for physiotherapy practice? What and how are we to practice following such radical critique?

In line with the growing body of work in critical physiotherapy, we believe that the principal benefit of the critical study of physiotherapy lies in exposing otherwise unnoticed and unreflected problems that pervade its theories and practices (Setchell, Nicholls, Wilson \& Gibson, 2018). In the present case, it is the exposure of an underlying, but as yet unseen act of violence at the heart of physiotherapy theory and practice because of its grounding in ontology and epistemology. By highlighting that this violence runs counter to our therapeutic aspiration to 'develop, maintain and restore people's maximum movement', we hope to open the door to other ways to imagine physiotherapy that are coherent with this aim (WCPT, 2016).

Before going on to point to a few other ways that the Levinassian critique of ontology might inspire an otherwise physiotherapy, we should acknowledge that the difficulty to put Levinassian ethics into practice has maybe been a significant point of contention in the reception of his work. This also includes the impossibility to escape ontology and epistemology, as much as (conscious) knowing and doing entirely. The issue has led to the outright dismissal of Levinassian ethics as impractical on the one hand, versus its assertion as 'the (only) basis for effective ethical action' on the other' (Zeillinger, 2009).

Going into the necessary detail of this discussion and how it might be resolved is beyond the scope of the present article. In the following, we outline a few ways in which we might at least approximate the mitigation of the violence of thematisation in physiotherapy practice. These ideas are closer in line with the latter position in this debate and a reading of Levinassian ethics that we have developed elsewhere, which additionally draws on a range of closely resonating Asian philosophies and practices in an attempt to provide an otherwise resolution to the problem of practising Levinassian ethics (Maric, 2017).

The overarching implication of Levinas's critique of ontology lies in its call to interrupt our conventional ways of thinking and doing physiotherapy, in full recognition of the underlying harm they cause. This is a profoundly disruptive call since virtually all of our professional self-understanding and sense of agency builds on knowledge and practices that thematise the other and the phenomena we encounter. Drawing on resonant Asian philosophical practices and, in a sense, thinking with Levinas in the extreme, we argue that the initial aim of an otherwise physiotherapy would have to be to refrain from or at least minimise the violence enacted in our professional knowledge and practices. We suggest and explore letting-go as an otherwise therapeutic practice in line with this aim by applying it to the physiotherapy theories and practices we have focussed on in this article. Its point is to reduce or 
minimise the iatrogenic violence incurred through the constraining grip of our professional knowledge and practices and so mobilise or liberate the other from their constraints.

Beginning with the aim of physiotherapy, we could say that Levinas's critique of ontology supports a person-centred approach to physiotherapy (Kidd, Bond, \& Bell, 2011, p. 155). This is specifically insofar as a critical aspect of person-centred care is to incorporate patient's aims 'needs and perspectives' in a way that is 'complementary to the traditional diagnostic and procedural hypothetico-deductive reasoning' (Cruz, Caeiro and Pereira, 2013, p. 6). In Levinasian terms, the integration of patients aims interrupts the possibility to define and thus delimit curative aims objectively and a priori. Withholding or even letting go of the latter entirely is all about minimising the restriction such external aims can incur and mobilising highly subjective and dynamic aims to be formulated and continuously reformulated by (or in partnership with) our patients.

However, there is a limit to Levinas's potential support of patient-centred care in this regard, where patient's aims are only made space for as a proxy for a new and different thematisation (Armstrong, 1999). That is, if we are only 'listening attentively' to our client's aims and hopes as a pathway to rigidly defined diagnosis and treatment after all (Burcher, 2011, p. 13). With Levinas, we must do something more radical if we are to truly relate to 'patients in a manner that respects their alterity and otherness' (Clifton-Soderstrom, 2013, p. 458). Beyond merely listening attentively for the same final purpose as before, the critique of thematisation urges us to hesitate far more rigorously (Ronell \& Dufourmantelle, 2011). It suggests making this hesitation a continuous practice, an ongoing effort of 'staying open to the full speech and discourse of the other', as suggested by Adam (2016) in a resonant discussion of Lacanian psychoanalysis (p. 119, emphasis added).

The idea of letting go and staying open in practice is further clarified if applied to the practice of diagnosis. In relation to diagnostic practices, it would consist of continuously refraining 'from representing and offering a closed knowledge' to the client and then implementing this as the basis of practice (Translated from Adam, 2006, p. 119). The focus of practice would not be on identifying a specific pathology and treating only this according to a set of professional standards. Instead, it would be to shift our focus to continuously acknowledging, rehabilitating, or mobilising the possibility that every client and every client's malady could just be different from what we think, time and time again. It is mobilising difference, otherness or diversity in a much more radical manner. Not just qualifying our diagnosis as potentially 'provisional', but not applying a diagnostic label at all, not closing a category (ACC, 2019).
Extending this to the notion and creation of professional identity, Levinas's critique of ontology also supports current developments in reviewing and promoting diversity in physiotherapy (Andrion, 2017; Ross \& Setchell, 2019). But here as well, it effectively urges us to let go of the notion of professional identity and the restrictive practices we engage in its wake. In this sense, it also goes further than expanding professional identity according to diversity defined as inclusivity of one or another (group of) persons, which inevitably always implies excluding others. At a baseline, the Levinassian critique of (professional) identity adds sensitivity and strength to the call for a physiotherapy theory and practice based on a full acknowledgement and preservation of the fundamental otherness of other persons, client or practitioner (Clifton-Soderstrom, 2013, p. 458; Critchley, 2002, p. 26). Well beyond this, however, it calls for a radical openness to any kind of other (or otherness), for diversity, paradoxically, defined as openness. This, in turn, requires a rigorous and continuous letting-go wherever the inclination to restrict reappears.

More poignantly, the idea and practice of letting go of our professional identity as we have understood it so far - defined by professional knowledge, aims and practices - invites a fundamental review of how we understand and relate to our personal and professional selves, as well as the others in our care. The opportunity provided by Levinas's critique of ontology and the violence of thematisation is precisely the radical cutting back to nearly nothing. It seems to us that this 'taking the house down' is necessary before we begin to build a new one. Though we have not been able to explore this in the present article, this is also where the full strength and benefit of Levinas's work for physiotherapy actually lies. That is, not only in the astute critique of our hitherto identity and concomitant practices but also in providing a rich resource for imagining an otherwise physiotherapy that is not grounded in being, knowledge and doing.

\section{Conclusion}

Drawing on Levinas's critique of ontology highlights how the fundamental violence of thematisation pervades physiotherapy theory and practice. It can be traced through its positivist, biomedical philosophical and scientific foundations, through our professional self-understanding and agency, and even our most common day-to-day practices. This radical questioning of the professional has concrete implications for physiotherapy theory, practice, and education. It supports contemporary advances in person-centred healthcare by highlighting the need to acknowledge and preserve their particularity in theory and practice at all times. Reaching well beyond this, however, Levinas's critique of ontology challenges us to fundamentally review how we relate to ourselves and those in our care. It asks us to reconsider how 
our critical professional work might be grounded in other foundations than ontology and epistemology, which, with Levinas, implies a grounding in fundamental ethics.

This is also of critical import to physiotherapy education insofar as it is in education that professional agency and a first sense and understanding of professional identity are developed and can, therefore, be transformed in the most lasting manner. Building the critique of ontology, the central focus of Levinas's work was on describing a different, ethical relationship between self and other. Consequently, his work is of twofold interest to physiotherapy theory and practice. On the one hand, in the critical sense laid out in the present article and, on the other, in its potential to inspire an otherwise physiotherapy theory and practice in the future. There is ample space for future research then, to explore what might be considered the productive potential, but also the limitations of Levinas's work that follow the critique of ontology that we have focussed on here.

\section{References}

Accident Compensation Corporation/ACC. (2019).

Understanding your responsibilities. Accident Compensation Corporation (ACC). Wellington, NZ: Retrieved May 10, 2019, from

https://www.acc.co.nz/for-providers/provide-services/unders tanding-your-responsibilities/

Adam, J. (2006). Ich und das Begehren in den Fluchten der Signifikanten. Oldenburg, Germany: BIS Verlag.

Allen, D. (2007). Proposing 6 dimensions within the construct of movement in the movement continuum theory. Physical Therapy, 87(7), 888-898. doi:10.2522/ptj.20060182

Andrion J. IEPT: Imagining an encompassing physiotherapy. Physiotherapy Practice (Canada) - Diversity in Practice Issue. 2017;7(2).

Armstrong, M. (1999). Face to face with child abuse: towards an ethics of listening. Law and Critique, 10, 147-173.

Bähr, A. (2014). Die Bedeutung der wahrnehmenden Berührung im physiotherapeutischen Prozess: Eine explorative Studie (Dissertation). Universität Hildesheim, Hildesheim, Germany.

Beavers, A. (1990). Introducing Levinas to undergraduate philosophers. Colloquy paper, Undergraduate Philosophy Association, University of Texas. Austin.
Bergo, B. (2007). Emmanuel Levinas. In E. N. Zalta (Ed.), The Stanford encyclopedia of philosophy (August 2010).

Retrieved October 2019 from

http://plato.stanford.edu/entries/levinas/

Bernstein, R. (2002). Evil and the temptation of theodicy. In S. Critchley \& R. Bernasconi (Eds.), The Cambridge Companion to Levinas (pp. 252-267). Cambridge, UK: Cambridge University Press.

Burcher, P. (2011). The noncompliant patient: A Kantian and Levinasian response. Journal of Medicine and Philosophy, $O$, 1-16. doi:10.1093/jmp/jhro58

Clifton-Soderstrom, M. (2003). Levinas and the patient as Other: the ethical foundation of medicine. The Journal of Medicine \& Philosophy, 28(4), 447-460.

doi:10.1076/jmep.28.4.447.15969

Cott, C., Finch, E., \& Gasner, D. (1995). The movement continuum theory of physical therapy. Physiotherapy Canada, 47(2), 87.

Critchley, S. (2002). Introduction. In S. Critchley \& R. Bernasconi (Eds.), The Cambridge Companion to Levinas (pp. 1-32). Cambridge: Cambridge University Press.

Crotty, M. (1998). The foundations of social research: Meaning and perspective in the research process. Thousand Oaks: Sage.

Cruz, E., Caeiro, C., \& Pereira, C. (2013). A narrative reasoning course to promote patient-centred practice in a physiotherapy undergraduate programme: a qualitative study of final year students. Physiotherapy Theory and Practice, Early Online, 1-7. doi:10.3109/09593985.2013.863415

Dahl-Michelsen, T., \& Groven, K. (2017). How do we learn professional ethics? Professional competences, embodiment and ethics in physiotherapy education in Norway. CriSTal Critical Studies in Teaching \& Learning, 5(1), 67-84. doi:10.14426/cristal.v5i1.100

Dufour, S.A., Brown, J. \& Lucy, D.S. (2014) Integrating physiotherapists within primary health care teams: perspectives of family physicians and nurse practitioners. Journal of Interprofessional Care, 28:5, 460-465, doi: 10.3109/13561820.2014.915210

Fagenblat, M. (2018). Levinas and Heidegger: The Elemental Confrontation. In M. Morgan (Ed.), The Oxford Handbook of Levinas. doi: 10.1093/oxfordhb/9780190455934.013.18

Gibson, B. (2014). Parallels and problems of normalization in rehabilitation and universal design: enabling connectivities. 
Disability and Rehabilitation, 36(16), 1328-1333.

doi:10.3109/09638288.2014.891661

Gibson, B., \& Martin, D. (2003). Qualitative research and evidence-based physiotherapy practice. Physiotherapy, 89(6), 350-358. doi:10.1016/Soo31-9406(05)60027-2

Gibson, B., Nicholls, D., Setchell, J., \& Groven, K. (Eds.). (2018). Manipulating practices: A critical physiotherapy reader. Norway: Cappellen Damm Akademisk.

Gibson, B., \& Teachman, G. (2012). Critical approaches in physical therapy research: Investigating the symbolic value of walking. Physiotherapy Theory and Practice, 28(6), 474-484. doi:10.3109/09593985.2012.676936

Giddings, L., \& Grant, B. (2007). A trojan horse for positivism? A critique of mixed methods research. Advances in Nursing Science, 3o(1), 52-60.

Grant, B., \& Giddings, L. (2002). Making sense of methodologies: A paradigm framework for the novice researcher. Contemporary Nurse: A Journal for the Australian Nursing Profession, 13(1), 10-28.

Greenhalgh, T., Howick, J., \& Maskrey, N. (2014). Evidence based medicine: a movement in crisis? British Medical Journal. doi:10.1136/bmj.g3725

Harper, D. (2019). mobile (adj.). Online Etymology Dictionary. Lancaster, PA: Retrieved April 10, 2019, from https://www.etymonline.com/word/mobile\#etymonline_v_1 7360

Heidegger, M. (2008). Being and Time (J. Macquarrie \& E. Robinson, Trans.). New York, NY: Harper Collins.

Holmes, D., Murray, S. J., Perron, A., \& Rail, G. (2006). Deconstructing the evidence-based discourse in health sciences: truth, power and fascism. International Journal of Evidence-Based Healthcare, 4(3), 180-186.

doi:10.1111/j.1479-6988.2006.00041.x

Jorgensen, P. (2000). Concepts of body and health in physiotherapy: The meaning of the social/cultural aspects of life. Physiotherapy Theory and Practice, 16(2), 105-115. doi:10.1080/095939800407295

Kidd, M., Bond, C., \& Bell, M. (2011). Patients' perspectives of patient-centredness as important in musculoskeletal physiotherapy interactions: a qualitative study.

Physiotherapy(97), 154-162.

doi:10.1016/j.physio.2010.08.002
Korab-Karpowicz, W. (2019). Martin Heidegger (1889-1976). In J. Fieser \& B. Dowden (Eds.), Internet Encyclopedia of Philosophy. Retrieved April 10, 2019, from https://www.iep.utm.edu/heidegge/

Kulju, K., Suhonen, R., \& Leino-Kilpi, H. (2013). Ethical problems and moral sensitivity in physiotherapy: A descriptive study. Nursing Ethics, 2O(5), 568-577.

doi:10.1177/0969733012468462

Levinas, E. (1969). Totality and Infinity: An Essay on Exteriority (A. Lingis, Trans.). Pittsburgh, PA: Duquesne University Press.

Levinas, E. (1987). Collected Philosophical Papers (A. Lingis, Trans.). Dordrecht, NL: Martinus Nijhoff Publishers.

Levinas, E. (1989). Ethics as First Philosophy (S. Hand \& M. Templè, Trans.). In S. Hand (Ed.), The Levinas Reader: Emmanuel Levinas (pp. 75-87). Oxford, UK: Basil Blackwell Ltd.

Levinas, E. (1990). Difficult freedom: Essays on Judaism (S. Hand, Trans.). Baltimore: Johns Hopkins University Press.

Levinas, E. (1995). The Theory of Intuition in Husserl's Phenomenology (A. Orianne, Trans.). Evanston: Northwestern Univ Press.

Levinas, E., \& Anissimov, M. (2001). Interview with Myriam Anissimov (J. Robbins, \& T. Loebel, Trans.). In J. Robbins (Ed.), Is It Righteous To Be? Interviews with Emmanuel Levinas (pp. 84-92). Stanford, MA: Stanford University Press.

Levinas, E., \& Malka, S. (2001). Interview with Salomon Malka (J. Robbins, \& M. Coelen, Trans.). In J. Robbins (Ed.), Is It Righteous To Be? Interviews with Emmanuel Levinas (pp. 93-102). Stanford, MA: Stanford University Press.

Levinas, E., \& Nemo, P. (1985). Ethics and infinity. Pittsburgh, Pennsylvania: Duquesne University Press.

Levinas, E., \& Poirié, F. (2001). Interview with François Poirié (J. Robbins, M. Coelen, \& T. Loebel, Trans.). In J. Robbins (Ed.), Is It Righteous To Be? Interviews with Emmanuel Levinas (pp. 23-83). Stanford, MA: Stanford University Press.

Lillemoen, L., \& Pedersen, R. (2012). Ethical challenges and how to develop ethics support in primary health care. Nursing Ethics, 2O(1), 96-108. doi:10.1177/0969733012452687

Lund Kordahl, H. \& Fougner, M. (2017) Facilitating awareness of philosophy of science, ethics and communication through manual skills training in undergraduate education. 
Physiotherapy Theory and Practice, 33:3, 206-217, doi: 10.1080/09593985.2016.1277289

Malka, S. (2006). Emmanuel Levinas: His life and legacy (M. Kigel \& S. M. Embree, Trans.). Pittsburgh, Pennsylvania: Duquesne Univ Press.

Maric, F. (2017). Physiotherapy and Fundamental Ethics Questioning Self and Other in Theory and Practice (PhD Thesis). AUT University Auckland, New Zealand. Retrieved April 2020 from

https://openrepository.aut.ac.nz/handle/10292/11051

McManus, M. (2019). Why we should read Nietzsche. Quillette. Retrieved 11 May 2019, from

https://quillette.com/2019/04/22/why-we-should-read-nietz sche/

Miles, A., Loughlin, M., \& Polychronis, A. (2008).

Evidence-based healthcare, clinical knowledge and the rise of personalised medicine. Journal of Evaluation in Clinical Practice, 14, 621-649. doi:10.1111/j.1365-2753.2008.01094.x

Murray, S. \& Holmes, D. (Eds). (2009). Critical Interventions in the Ethics of Health Care. London: Routledge.

Naef, R. (2006). Bearing witness: a moral way of engaging in the nurse-person relationship. Nursing Philosophy, 7(3), 146-156. doi:10.1111/j..1466-769X.2006.00271.x

Nicholls, D. (2009). Qualitative research: Part one Philosophies. International Journal of Therapy and Rehabilitation, 16(10), 526-533.

Nicholls, D. (2018). The End of Physiotherapy. London, UK: Routledge.

Nicholls, D., \& Holmes, D. (2012). Discipline, desire, and transgression in physiotherapy practice. Physiotherapy Theory and Practice, 28(6), 454-465.

doi:10.3109/09593985.2012.676940

Nortvedt, P. (2003). Levinas, justice and health care. Medicine, Health Care and Philosophy, 6(1), 25-34. doi:10.1023/A:1022534902202

Physiotherapy Board of New Zealand/PBNZ. (2011). Aotearoa New Zealand Physiotherapy Code of Ethics and Professional Conduct with Commentary. Physiotherapy Board of New Zealand (PBNZ). Wellington, NZ: Retrieved July 29, 2012, from http://physioboard.org.nz/publications

Physiotherapy New Zealand/PNZ. (2012). Supervision in physiotherapy practice. Physiotherapy New Zealand (PNZ). Wellington, NZ: Retrieved April 03, 2014, from http://physiotherapy.org.nz/about-physiotherapy/profession al- guidelines/

Proietti, M., Pickston, A., Graffitti, F., Barrow, P., Kundys, D., Branciard, C., .. . Fedrizzi, A. (2019). Experimental rejection of observer-independence in the quantum world. Quantum Physics, arXiv:1902.05080.

Ronell, A., \& Dufourmantelle, A. (2011, February 12). The event of the encounter. The Other. [Video file]. Retrieved from https://youtu.be/IIm8tfE-ZiI

Rosberg, S. (2000). Body, being and meaning in a physiotherapeutic perspective. Thesis, Department of Social Work. University of Gothenburg, Sweden.

Ross, M., \& Setchell, J. (2019). People who identify as LGBTIQp can experience assumptions, discomfort, some discrimination, and a lack of knowledge while attending physiotherapy: a survey. Journal of Physiotherapy, 65, 99-105. doi:10.1016/j.jphys.2019.02.002

Setchell, J., Nicholls, D., Wilson, N., \& Gibson, B. (2018). Infusing rehabilitation with critical research and scholarship: A call to action. Physiotherapy Canada, 70(4), 301-305. doi:10.3138/ptc.70.4.gef

Shaw, J. (2012). Physiotherapy as bricolage: Theorizing expert practice. Physiotherapy Theory and Practice, 28(6), 420-427. doi:10.3109/09593985.2012.676941

Surbone, A. (2005). Recognizing the patient as "other". Supportive Care in Cancer, 13(1), 2-4. doi:10.1007/so0520-004-0744-9

Swisher, L. (2002). A retrospective analysis of ethics knowledge in physical therapy (1970 -2000). Physical Therapy, 82(7), 692-702.

von Wolzogen, C. (2005). Emmanuel Levinas - Denken bis zum Äußersten. München, Germany: Verlag Karl Alber

World Confederation for Physical Therapy/WCPT (2011a) WCPT guideline for delivering quality continuing professional development for physical therapists. London, UK: World Confederation for Physical Therapy (WCPT). Retrieved March 2013 from http://www.wcpt.org/guidelines/CPD

World Confederation for Physical Therapy/WCPT (2011b) WCPT guideline for physical therapist professional entry level education. London, UK: World Confederation for Physical Therapy (WCPT). Retrieved March 2013 from http://www.wcpt.org/guidelines/entry- level-education 
World Confederation for Physical Therapy/WCPT (2016).

What is physical therapy? London, UK: World Confederation for Physical Therapy (WCPT). Retrieved March 2013 from http://www.wcpt.org/what-is- physical-therapy

World Health Organization/WHO. (2002). International Classification of Functioning, Disability and Health (ICF). Geneva, Switzerland: World Health Organization (WHO). Retrieved August 2012 from http://www.who.int/classifications/icf/training/icfbeginnersg uid e.pdf

World Health Organization/WHO. (1948). Preamble to the Constitution of the World Health Organization as adopted by the International Health Conference, New York, 19-22 June, 1946; signed on 22 July 1946 by the representatives of 61 States (Official Records of the World Health Organization, no. 2, p. 100) and entered into force on 7 April 1948.

Wikström-Grotell, C., \& Eriksson, K. (2012). Movement as a basic concept in physiotherapy - A human science approach. Physiotherapy Theory and Practice, 28(6), 428-438.

doi:10.3109/09593985.2012.692582

Zeillinger, P. (2009). Radical Passivity as the (Only) Basis for Effective Ethical Action. Reading the 'Passage to the Third ' in Otherwise than Being. In B. Hofmeyr (Ed.), Radical Passivity: Rethinking Ethical Agency in Levinas (pp. 95-108).

Dordrecht: Springer.

\section{Peer review reports}

Anna Rajala (a.rajala@brighton.ac.uk)

Reviewed: 30 July 2019

Citation: Rajala, A. (2019). The fundamental violence of physiotherapy: Emmanuel Levinas's critique of ontology and its implications for physiotherapy theory and practice. OpenPhysio.

Dorothee Holscher (d.holscher@griffith.edu.au)

Reviewed: 03 December 2019

Citation: Holscher, D. (2019). The fundamental violence of physiotherapy: Emmanuel Levinas's critique of ontology and its implications for physiotherapy theory and practice. OpenPhysio. 